\section{Ethanol ablation as a treatment strategy for benign cystic thyroid nodules: a comparison of the ethanol retention and aspiration techniques}

\author{
Hye Sun Park ${ }^{1 *}$, Younghee Yim ${ }^{2 *}$, Jung Hwan Baek', Young Jun Choi ${ }^{1}$, Young Kee Shong ${ }^{3}$, \\ Jeong Hyun Lee ${ }^{1}$ \\ 'Department of Radiology and Research Institute of Radiology, Asan Medical Center, \\ University of Ulsan College of Medicine, Seoul; ${ }^{2}$ Department of Radiology, Kangwon \\ National University Hospital, Kangwon National University School of Medicine, Chuncheon; \\ ${ }^{3}$ Department of Metabolism and Endocrinology, Asan Medical Center, University of Ulsan \\ College of Medicine, Seoul, Korea
}

Purpose: We compared the efficacy and safety of two ethanol ablation techniques-ethanol aspiration and ethanol retention-for benign cystic thyroid nodules.

Methods: From October 2008 to September 2013, 113 patients who were treated using the ethanol aspiration technique (February 2008 to December 2010) and 108 patients who were treated using the ethanol retention technique (January 2011 to September 2013) were enrolled (male:female ratio, 53:168; mean age, 48.1 years; range, 18 to 80 years). The patient sample had 94 cystic and 127 predominantly cystic thyroid nodules. The volume reduction ratio (VRR) at the last follow-up, improvements in symptoms and cosmetic scores, vascularity, pain, and major complications were evaluated and compared between the ethanol aspiration group and ethanol retention group. We also performed a subgroup analysis according to the proportion of the solid component, in which VRR, symptom and cosmetic scores, and therapeutic success were compared.

Results: No statistically significant difference in VRR was found between the ethanol retention group and the ethanol aspiration group $(83.2 \% \pm 32.8 \%$ vs. $86.1 \% \pm 18.4 \%, P=0.416)$ while patients who underwent the retention technique were more likely to experience pain after treatment $(P=0.001)$. VRR, symptom and cosmetic scores, and therapeutic success did not significantly differ between techniques in either group in the subgroup analysis.

Conclusion: The ethanol aspiration technique may be preferable to the ethanol retention technique for treating benign cystic and predominantly cystic thyroid nodules, because a comparable VRR can be expected with less pain.

Keywords: Thyroid nodule; Ultrasonography; Ethanol; Ablation

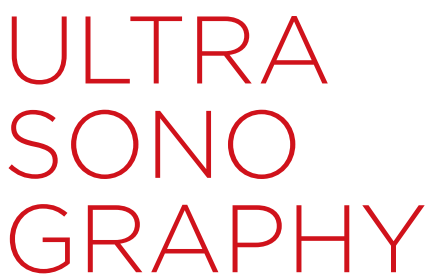

\section{ORIGINAL ARTICLE}

https://doi.org/10.14366/usg.18033 pISSN: 2288-5919 • elSSN: 2288-5943 Ultrasonography 2019;38:166-171

Received: June 1, 2018

Revised: July 30, 2018

Accepted: August 1, 2018

Correspondence to: Jung Hwan Baek, MD, PhD, Department of Radiology and Research Institute of Radiology, Asan Medical Center, University of Ulsan College of Medicine, 88 Olympic-ro 43-gil, Songpa-gu, Seoul 05505, Korea

Tel. $+82-2-3010-4348$

Fax. +82-2-476-0090

E-mail: radbaek@naver.com

* Hye Sun Park and Younghee Yim contributed equally to this work.

This is an Open Access article distributed under the terms of the Creative Commons Attribution NonCommercial License (http://creativecommons.org/ licenses/by-nc/4.0/) which permits unrestricted noncommercial use, distribution, and reproduction in any medium, provided the original work is properly cited.

Copyright (C) 2019 Korean Society of Ultrasound in Medicine (KSUM)

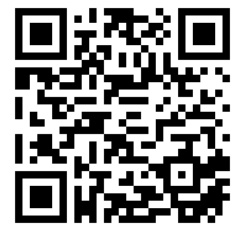

How to cite this article:

Park HS, Yim Y, Baek JH, Choi YJ, Shong YK, Lee JH. Ethanol ablation as a treatment strategy for benign cystic thyroid nodules: a comparison of the ethanol retention and aspiration techniques. Ultrasonography. 2019 Apr;38(2):166-171. 


\section{Introduction}

As the incidence of thyroid nodules has increased, ultrasonography (US)-guided ablation techniques have become widely used to treat benign thyroid nodules $[1-4]$ and recurrent thyroid cancers $[5,6]$. Even though simple aspiration has been suggested as the first-line management tool for both diagnostic and therapeutic purposes in patients with benign cystic thyroid nodules, a high recurrence rate has been reported, depending on the number and volume of the aspirated cysts. US-guided ethanol ablation (EA) has been recommended as powerful treatment strategy for symptomatic benign cystic (no solid portion) or predominantly cystic (cystic portion $>50 \%$ ) thyroid nodules [7-9], and it has been shown to be effective and safe in previous studies $[10,11]$.

Two different types of EA techniques have been used; one is the ethanol retention technique, which refers to the retention of injected ethanol inside the cystic cavity of the nodule [12], and the other is the ethanol aspiration technique, in which the injected ethanol is completely aspirated after several minutes [11]. Generally, EA involves removing the cystic fluid from the thyroid nodule and then injecting a volume of $99 \%$ ethanol corresponding to roughly $50 \%$ of the aspirated fluid volume. Some authors have argued that the injected ethanol should be aspirated, as doing so can prevent complications such as pain and/or perithyroidal fibrosis due to ethanol leakage [13]. In contrast, the retention technique might be preferable since it is technically simple and can save time [12]. Some authors have suggested that the sustained presence of ethanol can result in continuous coagulative necrosis, small vessel thrombosis, hemorrhagic infarction, and reactive fibrosis, which might provide a delayed ablation effect, especially for predominantly cystic nodules $[14,15]$.

To our knowledge, very few studies have compared the efficacy and safety of the retention and aspiration techniques. For example, Kim et al. [12] suggested that percutaneous ethanol injection without the aspiration of ethanol-mixed fluid seemed to be the preferable method for treating benign cystic thyroid nodules because of the simplicity of the procedure. Therefore, we compared the efficacy of these two techniques in treating benign cystic and predominantly cystic thyroid nodules.

\section{Materials and Methods}

\section{Study Design}

This retrospective observational study was approved by the Institutional Review Board of our institution. Informed consent for US-guided procedures was obtained from all patients prior to each procedure.
In this study, we enrolled 113 patients who were treated using the ethanol aspiration technique (from February 2008 to December 2010) and 118 patients who were treated using the ethanol retention technique (from January 2011 to September 2013). The inclusion criteria were as follows: (1) a thyroid nodule with a cystic proportion greater than $50 \%$; (2) the presence of pressure symptoms or cosmetic problems; (3) serum levels of thyroid hormones, thyrotropin, and calcitonin within normal limits; (4) cytological confirmation that the lesion was benign after two separate US-guided fine needle aspiration (FNA) biopsies [16,17]; and (5) no malignant features on US examinations (i.e., a tallerthan-wide shape, a spiculated margin, marked hypoechoicity, or the presence of microcalcifications) [18].

\section{Pre-enrollment Procedures and Assessment}

The US, US-guided FNA, and laboratory and clinical results were evaluated before ablation. Two radiologists (J.H.B. and J.H.L., with 20 and 15 years of US thyroid experience, respectively) performed US and US-guided FNA using a 5-14 MHz linear probe fitted to a real-time US system (iU22 unit, Philips Healthcare, Bothell, WA, USA; Hitachi Logos E, EUB-7500, Hitachi Medical System, Tokyo, Japan). The nodule size, the proportion of the solid component, and vascularity were assessed. The three orthogonal diameters (the largest diameter and 2 perpendicular diameters) and volume of each nodule were evaluated [19]. Nodules without an obvious solid component were classified as cystic, whereas those with a cystic component of more than $50 \%$ were classified as predominantly cystic $[9,10]$. Vascularity was graded using four categories (grade 0 , no intranodular vascularity; grade 1, perinodular vascularity only; grade 2, intranodular vascularity $<50 \%$; and grade 3 , intranodular vascularity $>50 \%$ ) [11]. At enrollment, patients were asked to rate their symptom score on a $10-\mathrm{cm}$ visual analogue scale, and their cosmetic grade was recorded by a physician (1, no palpable mass; 2 , a palpable mass but no cosmetic problem; 3 , a cosmetic problem only apparent upon swallowing; and 4 , a readily detected cosmetic problem) [20].

\section{Procedure}

All procedures were performed in an outpatient setting. Patients were placed in a supine position with mild neck extension. After skin sterilization and anesthesia with $2 \%$ lidocaine at the puncture site, a 16- to 18-gauge needle was inserted into the nodule under US guidance using the transisthmic approach [11]. The internal fluid was aspirated to the maximum extent possible, and saline irrigation was used to remove residual debris and/or colloid. Ethanol (99\%) was then injected slowly into the cystic cavity. The volume of injected ethanol usually corresponded to roughly $50 \%$ of the volume of the 
aspirated fluid. In the retention group, the injected ethanol was not removed after the procedure, whereas in the aspiration group, it was completely removed after 2-5 minutes based on the nodule size and operator's preference $[11,21,22]$. In this study, we used a single-puncture technique for ethanol aspiration (i.e., retention of ethanol with the needle in place, followed by aspiration of ethanol after a few minutes) which can reduce discomfort due to additional needling during aspiration, as discussed in a previous study [12]. During and immediately after the procedure, the presence of any discomfort or complications was evaluated. Procedure-related pain was graded using four categories (grade 0 , no pain or mild pain similar to the pain experienced during the lidocaine injection; grade 1, pain greater than the lidocaine injection, but not needing medication; grade 2, pain needing medication; and grade 3, EA procedure terminated before completion due to severe pain) [11]. Patients stayed in the hospital for 30 minutes after the procedure for observation.

The volume reduction ratio (VRR) was defined as

$$
\operatorname{VRR}(\%)=\frac{\text { Initial volume-Post-treatment volume }}{\text { Initial volume }} \times 100
$$

\section{Follow-up}

US examinations were performed in all patients at 1-, 6-, and 12-month follow-up examinations. After 1 year of treatment, an US examination was performed annually. Treatment efficacy was evaluated by measuring the VRR, therapeutic success (VRR $>50 \%$ ) $[23,24]$, and vascularity of the treated thyroid nodules on US, and by assessing the improvement of symptoms and cosmetic problems [11]. Any adverse events, including pain, were recorded. Repeat EA or radiofrequency ablation (RFA) was performed on patients with nodules showing a VRR $<50 \%$ or a residual solid portion with internal vascularity on a follow-up US examination, and/or incompletely resolved symptoms (symptom score reduction $<50 \%$ ) or cosmetic problems $[25,26]$.

\section{Statistical Analyses}

We compared the VRR, symptom and cosmetic score, vascularity, and complications between the ethanol retention and aspiration groups. A subgroup analysis was conducted according to the proportion of the solid component, and the VRR, symptom and cosmetic scores, and therapeutic success were compared in this analysis as well. The Fisher exact test and the Wilcoxon signed-rank test were used for the analyses. P-values $<0.05$ were considered to indicate significant differences. All statistical analyses were performed using SPSS for Windows ver. 18.0 (SPSS Inc., Chicago, IL, USA).

\section{Results}

From January 2011 to September 2013, 118 patients treated using the ethanol retention technique were identified as being eligible for enrollment in this study. Ten patients were lost to follow-up. As a result, the retention group included 108 patients. By contrast, 113 patients treated using the ethanol aspiration technique between October 2008 and December 2010 were enrolled (27 males and 86 females; mean age \pm standard deviation, $48.7 \pm 12.4$ years; range, 27 to 78 years). Therefore, a total of 221 patients (108 treated using the retention technique and 113 treated using the ethanol aspiration technique) were ultimately included in this study. The baseline characteristics of the patients in the two groups are summarized in Table 1.

Table 1. Demographic characteristics of the enrolled patients

\begin{tabular}{|c|c|c|c|}
\hline Characteristic & Retention $(n=108)$ & Aspiration $(n=113)$ & P-value \\
\hline No. of men/women & $26(24.1) / 82(75.9)$ & $27(23.9) / 86(76.1)$ & 0.975 \\
\hline Age (yr) & $47.5 \pm 12.7(18-80)$ & $48.7 \pm 12.4(27-78)$ & 0.473 \\
\hline Nodule diameter (cm) & $3.6 \pm 1.4(1.6-10.2)$ & $3.9 \pm 1.3(1.4-9.5)$ & 0.050 \\
\hline Nodule volume (mL) & $18.0 \pm 29.9(0.8-266.3)$ & $18.3 \pm 17.6(1-110)$ & 0.093 \\
\hline Vascularity & & & 0.013 \\
\hline None (grade 0) & $50(46.3)$ & $34(30.3)$ & \\
\hline Vascularity $(+$, grade $1-3)$ & $58(53.7)$ & $79(70.7)$ & \\
\hline Solidity & & & 0.799 \\
\hline Cystic (solid <10\%) & $45(41.7)$ & $49(43.4)$ & \\
\hline Predominantly cystic & $63(58.3)$ & $64(56.6)$ & \\
\hline Symptom score & $3.1 \pm 1.5(0-8)$ & $3.5 \pm 2.6(0-8)$ & 0.271 \\
\hline Cosmetic score & $3.9 \pm 0.4(1-5)$ & $3.9 \pm 0.3(2-4)$ & 0.337 \\
\hline
\end{tabular}

Values are presented as number (\%) or mean \pm standard deviation (range). 
The outcomes of the retention and aspiration groups at the last follow-up are summarized in Table 2. The mean follow-up period was 13.9 \pm 9.2 months (range, 1 to 31 months) in the retention group and $14.2 \pm 12.1$ months (range, 1 to 36 months) in the aspiration group $(\mathrm{P}=0.836)$.

The VRR did not show a statistically significant difference between the two groups, as it was $83.2 \% \pm 32.8 \%$ (range, $-147.2 \%$ to $100 \%$ ) in the retention group and $86.1 \% \pm 18.4 \%$ (range, $8 \%$ to $100 \%)$ in the aspiration group ( $P=0.416)$. The mean symptom scores, cosmetic scores, and vascularity were not significantly different between the retention and aspiration groups $(P=0.677$, $P=0.277$, and $P=0.062$, respectively). There were no major complications in either group ( $P>0.99$ ), although pain during the procedure was significantly greater in the retention group $(P=0.001)$.

The subgroup analysis according to the proportion of the solid component is summarized in Table 3. No significant differences were found between the retention and aspiration groups in the cystic and predominantly cystic subgroups in the mean VRR at the last followup, symptom score, cosmetic score, or therapeutic success $(P=0.364$, $P=0.129, P=0.671$, and $P=0.206$ in cystic nodules, respectively;
$\mathrm{P}=0.761, \mathrm{P}=0.710, \mathrm{P}=0.118$, and $\mathrm{P}=0.070$ in predominantly cystic nodules, respectively).

\section{Discussion}

This study showed that both the ethanol retention and aspiration techniques were safe and effective for the treatment of cystic and predominantly cystic thyroid nodules. The VRR was not significantly different between the ethanol aspiration and retention groups. Neither technique was associated with any major complications, although pain was significantly greater in the retention group. Therefore, ethanol aspiration may be preferable for treating benign cystic and predominantly cystic thyroid nodules, because we can expect a comparable VRR with less pain. In the subgroup analysis, the retention technique showed no benefit for either cystic or predominantly cystic nodules.

Regarding the treatment of cystic and predominantly cystic nodules, previous randomized clinical trials $[10,21]$ and guidelines [16] have suggested that EA is an effective treatment strategy that is preferable to RFA. However, the advantages and disadvantages

Table 2. Outcomes in the ethanol retention and aspiration groups after ethanol ablation

\begin{tabular}{lccc}
\multicolumn{1}{c}{ Outcome } & Retention $(\mathrm{n}=108)$ & Aspiration $(\mathrm{n}=113)$ & P-value \\
\hline Volume reduction ratio (\%) & $83.2 \pm 32.8(-147.2$ to 100) & $86.1 \pm 18.4(8$ to 100) & 0.416 \\
Symptom score & $0.5 \pm 0.9(0$ to 5$)$ & $0.5 \pm 0.8(0$ to 5$)$ & 0.677 \\
Cosmetic score & $1.8 \pm 1.0(0$ to 4$)$ & $1.7 \pm 1.0(1$ to 4$)$ & 0.277 \\
Vascularity & & & 0.062 \\
None (grade 0) & $68(63.0)$ & $58(51.3)$ & $55(48.7)$ \\
Vascularity (+, grade 1-3) & $40(37.0)$ & None & \\
Major complications & None & $0.1 \pm 0.4(0$ to 2) \\
Pain & $0.6 \pm 0.6(0$ to 2) & $99(87.6)$ \\
Grade 0 & $48(44.4)$ & $12(10.6)$ \\
Grade 1 & $56(51.9)$ & $2(1.8)$ \\
Grade 2 & $4(3.7)$ & 0.001 \\
\hline
\end{tabular}

Values are presented as mean \pm standard deviation (range) or number (\%).

Table 3. Subgroup analysis of cystic and predominantly cystic nodules

\begin{tabular}{|c|c|c|c|c|c|c|}
\hline & \multicolumn{3}{|c|}{ Cystic } & \multicolumn{3}{|c|}{ Predominantly cystic } \\
\hline & Retention $(n=45)$ & Aspiration $(n=49)$ & P-value & Retention $(n=63)$ & Aspiration $(n=64)$ & P-value \\
\hline VRR (\%) & $94.3 \pm 9.6(63.3$ to 100$)$ & $92.2 \pm 12.4$ (43.6 to 100$)$ & 0.364 & $74.9 \pm 40.5(-147.2$ to 100$)$ & $81.4 \pm 21.1$ (8 to 100$)$ & 0.761 \\
\hline Symptom score & $0.1 \pm 0.3$ (0 to 1) & $0.3 \pm 0.6$ ( 0 to 2 ) & 0.129 & $0.8 \pm 1.1$ (0 to 5$)$ & $0.7 \pm 1.0$ (0 to 5$)$ & 0.710 \\
\hline Cosmetic score & $1.2 \pm 0.6$ (0 to 3 ) & $1.4 \pm 0.9$ ( 1 to 4$)$ & 0.671 & $2.1 \pm 1.0$ (1 to 4$)$ & $1.9 \pm 1.0$ (1 to 4$)$ & 0.118 \\
\hline Therapeutic success & $44 / 45(97.8)$ & $44 / 49(89.8)$ & 0.206 & $52 / 63(82.5)$ & $44 / 64(68.8)$ & 0.070 \\
\hline
\end{tabular}

Values are presented as mean \pm standard deviation (range) or number (\%).

VRR, volume reduction ratio. 
of the retention and aspiration techniques are still under debate. Some authors prefer the retention technique due to its simplicity [12]. In a retrospective study by Kim et al. [12], the authors found no significant difference in the therapeutic success rate between the ethanol retention and aspiration techniques. Considering the higher incidence of intracystic hemorrhage on follow-up and the longer procedure time in the aspiration group, they concluded that the ethanol retention technique should be preferred. However, retained ethanol can cause extrathyroidal ethanol leakage, resulting in pain, voice change, and a feeling of intoxication [12,27-29]. Ethanol leakage into the perithyroid soft tissue can induce reactive fibrosis, which can be minimized by using the transisthmic approach $[20,30]$. Rare but serious complications related to extrathyroidal ethanol leakage, such as skin necrosis and venous thrombosis, have also been reported [13]. Therefore, we believe that the ethanol aspiration technique is safe and effective for treating benign cystic and predominantly cystic thyroid nodules.

It is known that the proportion of the solid component is a major predictive factor for the success of EA $[11,25]$. The solid component is relatively resistant to ethanol, and the vessels in the solid portion drain the ethanol, lowering the therapeutic efficacy of EA [22]. Additionally, vessels in the solid portion can cause internal bleeding during the follow-up period, which leads to treatment failure or recurrence of symptoms. When we performed a subgroup analysis according to the proportion of the solid component, no significant difference was found in the mean volume reduction between the two techniques in either the cystic or predominantly cystic group. Even though some studies have argued that the ethanol retention technique may be beneficial for predominantly cystic nodules, as the retained ethanol can diffuse into the solid portion and induce continuous ablation [14], our study did not show a statistically significant difference in the VRR or therapeutic success rate in either cystic thyroid nodules or predominantly cystic thyroid nodules.

The present study has several limitations. First, since this was a retrospective single-center study, selection bias may have been present. Further, the included population was relatively small, which could hamper the generalizability of our results.

In conclusion, ethanol aspiration may be preferable for treating benign cystic and predominantly cystic thyroid nodules, because we can expect a comparable VRR to that obtained using the ethanol retention technique, but with less pain.

ORCID: Hye Sun Park: https://orcid.org/0000-0003-0707-1875; Younghee Yim: https://orcid.org/0000-0002-4224-7832; Jung Hwan Baek: https://orcid.org/00000003-0480-4754; Young Jun Choi: https://orcid.org/0000-0001-7098-5042; Young Kee Shong: https://orcid.org/0000-0002-7911-9471; Jeong Hyun Lee: https://orcid.org/0000-0002-0021-4477

\section{Conflict of Interest}

No potential conflict of interest relevant to this article was reported.

\section{References}

1. Jeong WK, Baek JH, Rhim H, Kim YS, Kwak MS, Jeong HJ, et al. Radiofrequency ablation of benign thyroid nodules: safety and imaging follow-up in 236 patients. Eur Radiol 2008;18:1244-1250.

2. Spiezia S, Garberoglio R, Milone F, Ramundo V, Caiazzo C, Assanti $A P$, et al. Thyroid nodules and related symptoms are stably controlled two years after radiofrequency thermal ablation. Thyroid 2009;19:219-225.

3. Valcavi R, Riganti $F$, Bertani A, Formisano D, Pacella CM. Percutaneous laser ablation of cold benign thyroid nodules: a 3-year follow-up study in 122 patients. Thyroid 2010;20:12531261.

4. Zingrillo M, Torlontano M, Ghiggi MR, D'Aloiso L, Nirchio V, Bisceglia $M$, et al. Percutaneous ethanol injection of large thyroid cystic nodules. Thyroid 1996;6:403-408.

5. Lee SJ, Jung SL, Kim BS, Ahn KJ, Choi HS, Lim DJ, et al. Radiofrequency ablation to treat loco-regional recurrence of welldifferentiated thyroid carcinoma. Korean J Radiol 2014;15:817826.

6. Lim HK, Baek JH, Lee JH, Kim WB, Kim TY, Shong YK, et al. Efficacy and safety of radiofrequency ablation for treating locoregional recurrence from papillary thyroid cancer. Eur Radiol 2015;25:163170.

7. Lee YH, Baek JH, Jung SL, Kwak JY, Kim JH, Shin JH, et al. Ultrasoundguided fine needle aspiration of thyroid nodules: a consensus statement by the Korean Society of Thyroid Radiology. Korean J Radiol 2015;16:391-401.

8. Moon WJ, Baek JH, Jung SL, Kim DW, Kim EK, Kim JY, et al. Ultrasonography and the ultrasound-based management of thyroid nodules: consensus statement and recommendations. Korean J Radiol 2011;12:1-14.

9. Shin JH, Baek JH, Chung J, Ha EJ, Kim JH, Lee YH, et al. Ultrasonography diagnosis and imaging-based management of thyroid nodules: revised Korean Society of Thyroid Radiology consensus statement and recommendations. Korean J Radiol 2016;17:370-395.

10. Baek JH, Ha EJ, Choi YJ, Sung JY, Kim JK, Shong YK. Radiofrequency versus ethanol ablation for treating predominantly cystic thyroid nodules: a randomized clinical trial. Korean J Radiol 2015;16:13321340.

11. Kim YJ, Baek JH, Ha EJ, Lim HK, Lee JH, Sung JY, et al. Cystic versus predominantly cystic thyroid nodules: efficacy of ethanol ablation and analysis of related factors. Eur Radiol 2012;22:1573-1578.

12. Kim DW, Rho MH, Kim HJ, Kwon JS, Sung YS, Lee SW. Percutaneous ethanol injection for benign cystic thyroid nodules: is aspiration 
of ethanol-mixed fluid advantageous? AJNR Am J Neuroradiol 2005;26:2122-2127.

13. Mauz PS, Stiegler M, Holderried M, Brosch S. Complications of ultrasound guided percutaneous ethanol injection therapy of the thyroid and parathyroid glands. Ultraschall Med 2005;26:142-145.

14. Crescenzi A, Papini E, Pacella CM, Rinaldi R, Panunzi C, Petrucci $L$, et al. Morphological changes in a hyperfunctioning thyroid adenoma after percutaneous ethanol injection: histological, enzymatic and sub-microscopical alterations. J Endocrinol Invest 1996;19:371-376.

15. Livraghi T, Paracchi A, Ferrari C, Bergonzi M, Garavaglia G, Raineri P, et al. Treatment of autonomous thyroid nodules with percutaneous ethanol injection: preliminary results. Work in progress. Radiology 1990; 175:827-829.

16. Na DG, Lee JH, Jung $S L$, Kim JH, Sung JY, Shin JH, et al. Radiofrequency ablation of benign thyroid nodules and recurrent thyroid cancers: consensus statement and recommendations. Korean J Radiol 2012;13:117-125.

17. Haugen BR, Alexander EK, Bible KC, Doherty GM, Mandel SJ, Nikiforov YE, et al. 2015 American Thyroid Association management guidelines for adult patients with thyroid nodules and differentiated thyroid cancer: the American Thyroid Association Guidelines Task Force on Thyroid Nodules and Differentiated Thyroid Cancer. Thyroid 2016;26:1-133.

18. Russ G. Risk stratification of thyroid nodules on ultrasonography with the French TI-RADS: description and reflections. Ultrasonography 2016;35:25-38.

19. Choi YJ, Baek JH, Hong MJ, Lee JH. Inter-observer variation in ultrasound measurement of the volume and diameter of thyroid nodules. Korean J Radiol 2015;16:560-565.

20. Baek JH, Kim YS, Lee D, Huh JY, Lee JH. Benign predominantly solid thyroid nodules: prospective study of efficacy of sonographically guided radiofrequency ablation versus control condition. AJR Am J Roentgenol 2010;194:1137-1142.
21. Sung JY, Baek JH, Kim KS, Lee D, Yoo H, Kim JK, et al. Single-session treatment of benign cystic thyroid nodules with ethanol versus radiofrequency ablation: a prospective randomized study. Radiology 2013;269:293-300.

22. Park HS, Baek JH, Choi YJ, Lee JH. Innovative techniques for imageguided ablation of benign thyroid nodules: combined ethanol and radiofrequency ablation. Korean J Radiol 2017;18:461-469.

23. Ahn HS, Kim SJ, Park SH, Seo M. Radiofrequency ablation of benign thyroid nodules: evaluation of the treatment efficacy using ultrasonography. Ultrasonography 2016;35:244-252.

24. Yue WW, Wang SR, Lu F, Sun LP, Guo LH, Zhang YL, et al. Radiofrequency ablation vs. microwave ablation for patients with benign thyroid nodules: a propensity score matching study. Endocrine 2017; 55:485-495.

25. Jang SW, Baek JH, Kim JK, Sung JY, Choi H, Lim HK, et al. How to manage the patients with unsatisfactory results after ethanol ablation for thyroid nodules: role of radiofrequency ablation. Eur J Radiol 2012;81:905-910.

26. Lee JH, Kim YS, Lee D, Choi H, Yoo H, Baek JH. Radiofrequency ablation (RFA) of benign thyroid nodules in patients with incompletely resolved clinical problems after ethanol ablation (EA). World J Surg 2010;34:1488-1493.

27. Bennedbaek FN, Hegedus L. Treatment of recurrent thyroid cysts with ethanol: a randomized double-blind controlled trial. J Clin Endocrinol Metab 2003;88:5773-5777.

28. Monzani F, Lippi F, Goletti O, Del Guerra P, Caraccio N, Lippolis PV, et al. Percutaneous aspiration and ethanol sclerotherapy for thyroid cysts. J Clin Endocrinol Metab 1994;78:800-802.

29. Valcavi R, Frasoldati A. Ultrasound-guided percutaneous ethanol injection therapy in thyroid cystic nodules. Endocr Pract 2004;10:269-275.

30. Ha EJ, Baek JH, Lee JH. Ultrasonography-based thyroidal and perithyroidal anatomy and its clinical significance. Korean J Radiol 2015;16:749-766. 